\title{
PS4W: Programa de Inclusão Jovem e Feminina na Área Tecnológica
}

\author{
Nádia L. A. Alexandrino \\ IFMG/Instituto Federal de Minas Gerais \\ Sabará, Minas Gerais, Brasil \\ nadia28.alexandrino@gmail.com \\ Cristiane N. Targa \\ IFMG/Instituto Federal de Minas Gerais \\ Sabará, Minas Gerais, Brasil \\ cristiane.targa@ifmg.edu.br
}

\author{
Carlos A. Silva \\ IFMG/Instituto Federal de Minas Gerais \\ Sabará, Minas Gerais, Brasil \\ carlos.silva@ifmg.edu.br \\ Daniel B. F. Conrado \\ IFMG/Instituto Federal de Minas Gerais \\ Sabará, Minas Gerais, Brasil \\ daniel.conrado@ifmg.edu.br
}

\section{RESUMO}

A presença feminina em cursos e atividades profissionais relacionadas às áreas de exatas e de tecnologia é notadamente reduzida. De modo irreflexivo, meninas são afastadas dessas áreas, sendo submetidas predominantemente a comentários e brincadeiras que projetam tarefas domésticas, ao invés de trabalharem o raciocínio lógico e o pensamento computacional. Considerando estes fatores, o projeto de extensão Programa Sabará for Women (PS4W), exerce a missão de disseminar e estimular o desenvolvimento do pensamento computacional de meninas das escolas públicas da cidade mineira de Sabará. Para isso, foram lecionados conteúdos sobre raciocínio lógico, robótica e programação de computadores, orientados por meninas e mulheres que atuam na equipe do projeto. O PS4W representou uma grande experiência tanto para as instrutoras quanto para as alunas, as quais relataram possuir um interesse maior nas áreas de tecnologia ao fim do curso. O projeto também foi pauta de uma série de reportagem premiada nacionalmente e participou da Olimpíada Brasileira de Robótica, conquistando medalhas de honra ao mérito. Além disso, promoveu a formatura de mais de 80 alunas da rede pública de ensino da cidade, integrando as principais representações educacionais do município e do estado. A partir desses resultados foi possível perceber que o projeto se revelou como uma ação inovadora e de grande impacto na cidade. Ademais, a partir do desenvolvimento do PS4W, notou-se a necessidade de implementação de novas estratégias de ensino de tecnologia no município, e, por consequência, foram criados novos desdobramentos do projeto original, Programa Sabará, que vem beneficiando outros jovens da cidade.

\section{PALAVRAS-CHAVE}

meninas, escolas públicas, robótica, programação

Fica permitido ao(s) autor(es) ou a terceiros a reprodução ou distribuição, em parte ou no todo, do material extraído dessa obra, de forma verbatim, adaptada ou remixada, bem como a criação ou produção a partir do conteúdo dessa obra, para fins não comerciais, desde que sejam atribuídos os devidos créditos à criação original, sob os termos da licença CC BY-NC 4.0.

EduComp'21, Abril 27-30, 2021, Jataí, Goiás, Brasil (On-line)

(c) 2021 Copyright mantido pelo(s) autor(es). Direitos de publicação licenciados à Sociedade Brasileira de Computação (SBC).

\section{INTRODUÇÃO}

A lacuna entre gêneros existente na área de Tecnologia da Informação (TI) tem se tornado cada vez mais perceptível, sobretudo quando se trata dos níveis superiores de educação. Essa carência impacta negativamente mulheres que tentam ingressar na área, pois elas não conseguem se imaginar atuando ou se sentirem acolhidas em um ambiente predominantemente masculino. Essa é uma realidade tão clara, que Camila Achutti, CEO da Master Tech, em um dos vídeos ${ }^{1}$ da série de entrevistas "Mentes da Tecnologia" do canal The Enemy em parceria com a IBM, relatou que chegou a cogitar que o seu sonho de trabalhar na área de TI talvez não fosse "tão legal assim".

Esses fatores se agravam ao fato que a tecnologia vem sendo usada em larga escala para a solução de problemas, portanto se a tecnologia for dominada por um gênero específico, as soluções criadas tendem a beneficiar tal grupo.

O ensino de programação e robótica para meninas pode auxiliar o rompimento desse paradigma, e a partir disso, a proporcionalidade de mulheres na tecnologia poderá estar propensa a aumentar, formando equipes mais diversificadas e assim propondo soluções diversas para diferentes tipos de grupos.

O presente artigo relata a iniciativa do Programa Sabará em apoiar essa quebra de paradigma, criando um projeto que atua incentivando meninas e mulheres a se aventurarem na área de tecnologia, chamado Programa Sabará for Women (PS4W) na cidade mineira de Sabará. Este projeto foi financiado pelo edital CNPq/MCTIC $\mathrm{N}^{\circ}$ 31/2018 - Meninas nas Ciências Exatas, Engenharias e Computação do CNPq, que tinha por objetivo estimular a participação e a formação de meninas e mulheres para as carreiras de ciências exatas, engenharias e computação. Na chamada pública em questão, houveram mais de 700 projetos submetidos, sendo que no estado de Minas Gerais, apenas 8 foram aprovados e o PS4W foi um deles.

Este artigo de relato de experiência está dividido da seguinte forma. Na seção 1 foi apresentada uma breve contextualização da temática a qual o artigo aborda. A justificativa do trabalho é apresentada na seção 2, e sua fundamentação teórica, bem como experiências correlatas são apresentadas na seção 3. A metodologia do projeto norteador do artigo é descrita na seção 4 . Na seção 5 são relatadas as dificuldades apresentadas no decorrer do projeto,

\footnotetext{
${ }^{1}$ Disponível em: https://youtu.be/pjoKEkg_HIA. Acesso em 21 abr. 2020.
} 
e na seção 6 são discutidos os resultados alcançados. Por fim, as considerações finais são postas na seção 7 .

\section{JUSTIFICATIVA}

Embora o exercício profissional da programação seja naturalmente para especialistas, o seu ensino é extremamente necessário, sobretudo por dois fatores: o errôneo conceito sobre a geração $\mathrm{Z}$ e os benefícios de se desenvolver o pensamento computacional. $\mathrm{O}$ primeiro, explanado em 2016 por Camila Achutti no TEDx Dante Alighieri School ${ }^{2}$, se baseia no fato de que apesar das pessoas que compõem a geração $\mathrm{Z}$ saberem utilizar muito bem as tecnologias, elas em sua maioria não passam de superusuários, ou seja, não têm o real conhecimento sobre o que utilizam, o que os tornam facilmente manipuláveis. Em contrapartida, quando uma pessoa tem conhecimento do funcionamento das tecnologias que usa, passa também a saber que existem formas de não ser tão manipulável no meio tecnológico. Em relação ao segundo fator, o ensino de programação, inclusive na educação básica, pode promover o desenvolvimento do raciocínio lógico, da criatividade, e resolução de problemas, habilidades imprescindíveis para enfrentar os desafios atuais e futuros da sociedade [3].

Fato é que a área de tecnologia tende a crescer [7] e serão cada vez mais necessários profissionais atuando, portanto, como consequência a esta realidade, a preocupação com o ensino da programação tem se tornado cada vez maior nos últimos tempos e ganhou ainda mais força quando o ex-presidente dos Estados Unidos, Barack Obama, disse: "Não compre apenas um jogo, crie um. Não se limite a fazer download de uma nova aplicação, ajude a desenvolvê-la. Não jogue no seu celular, programe-o."3

Segundo o censo ${ }^{4}$ de 2018 do Instituto Brasileiro de Geografia e Estatística, o município de Sabará tem 47 estabelecimentos de ensino fundamental e 13 de ensino médio, mas, apesar da tendência mundial, não existe nenhuma escola voltada para o ensino de programação na cidade. Essa lacuna pode dificultar o avanço tecnológico no município, diminuindo a possibilidade de formação de profissionais especializados em tecnologia, afetando inclusive a economia local.

O município de Sabará esteve até 2017 classificado entre o G100, ou seja, entre os 100 municípios com mais de 80 mil habitantes com os menores valores de renda per capita e altos índices de vulnerabilidade social do país. Desta forma, grande parte do público atendido pertence à essa classe de vulnerabilidade. Além da capacitação tecnológica voltada a um público específico e minoritário, o projeto tem como finalidade promover a integração entre as instituições de ensino locais de diferentes modalidades, como ensino fundamental, ensino médio, ensino médio/técnico integrado e superior, e de distintas esferas governamentais como municipal, estadual e federal, e com a comunidade externa.

Nesse contexto, o projeto se mostra como uma tentativa de nutrir o setor de educação do município, capacitando meninas a seguirem na área de Tecnologia da Informação, a fim de, futuramente, tanto alavancar economicamente o município sabarense como quebrar o conceito de "coisas de menino" historicamente inculcado na mente

\footnotetext{
${ }^{2}$ Disponível em: https://youtu.be/dIxEGIiTRRc. Acesso em: 21 abr. 2020.

${ }^{3}$ Disponível em: https://youtu.be/zKkfF1QthZc. Acesso em: 29 abr. 2020

${ }^{4}$ Disponível em: https://cidades.ibge.gov.br/brasil/mg/sabara/panorama. Acesso em: 29 abr. 2020 .
}

das alunas, trazendo empoderamento às mesmas e desenvolvendo habilidades que poderão ser usadas em qualquer área.

\section{FUNDAMENTAÇÃO TEÓRICA}

De acordo com [6] há uma sub-representação das mulheres no sistema científico e tecnológico, tanto por uma exclusão horizontal, indicado por um baixo número de mulheres na área, quanto por uma exclusão vertical, apontando para um pequeno número de mulheres em postos de prestígio na área de tecnologia. Apenas $20 \%$ dos postos de trabalho na área de Tecnologia da Informação no Brasil são ocupados por mulheres, conforme relatado pela Associação para Promoção da Excelência do Software Brasileiro ${ }^{5}$ (SOFTEX). Uma das explicações para essa disparidade é dada por [9], que atribui sua causa à segregação horizontal, a qual induz meninas a escolherem determinadas carreiras influenciadas pela família e escola. Do ponto de vista econômico, a segregação de gênero na área de tecnologia da informação também é prejudicial. Diversas pesquisas na literatura como [13] e [2] abordam a segregação de gênero em ambientes de desenvolvimento tecnológico.

Uma projeção para 2025 da Mckinsey Global Institute, realizada em 2015, indica que a equidade de gênero no mundo poderia acrescentar aproximadamente US\$ 28 trilhões - ou $26 \%$ - ao PIB global. No cenário nacional, de acordo com o relatório global da Organização Internacional do Trabalho ${ }^{6}$ (OIT), divulgado em 2017, a economia brasileira poderia expandir em até $\mathrm{R} \$ 382$ bilhões ao longo de oito anos se aumentasse a inserção das mulheres no mercado de trabalho. Conforme os dados apurados por [15] é estimado que até 2022 haja um déficit de 408 mil profissionais da área de tecnologia da informação no Brasil, o que pode deixar de gerar uma receita de cerca de 138 bilhões de reais.

O presente artigo retrata a experiência de um projeto de inclusão digital feminina, o qual compõe, junto a iniciativas como MariaLab, PyLadies São Paulo, PrograMaria, \#MinasProgramam, dentre outros, projetos que tem ofertado atividades gratuitas por meio de cursos, encontros e palestras, aproximando as mulheres da tecnologia e as capacitando para as necessidades da sociedade atual. Outro exemplo é o programa Meninas Digitais, da Sociedade Brasileira de Computação ${ }^{7}$, cujo objetivo é colaborar no processo de empoderamento das meninas na área de tecnologia e na formação das futuras gerações de mulheres deste segmento, facilitando sua empregabilidade e sociabilização. Essas iniciativas são importantes e precisam ser incentivas e divulgadas para que o número de mulheres nas áreas de exatas seja ampliado.

Diversos trabalhos na literatura relatam casos bem sucedidos da inclusão digital feminina e/ou inclusão e motivação em atividades ligadas às áreas de exatas no período escolar. Em [10] são discutidas questões de igualdade de gênero no ensino médio e a inclusão de jovens nas áreas STEM (Science, Technology, Engineering, Mathematics). No trabalho são utilizadas dezenas de fontes acadêmicas-científicas sobre a temática e é descrito o projeto "Elas nas Ciências: um estudo sobre a equidade de gênero o ensino médio", o qual mapeou elementos que auxiliariam a tomada de decisão das

\footnotetext{
${ }^{5}$ Disponível em: https://www.ftp.softex.br/Inteligencia/mulheres_na_ti/mulheres_na_ ti.pdf. Acesso em: 11 jan. 2021.

${ }^{6}$ Disponível em: https://www.ilo.org/wcmsp5/groups/public/---dgreports/--dcomm/---publ/documents/publication/wcms 540901.pdf. Acesso: 12 de out 2020

${ }^{7}$ Disponível em: http://meninas.sbc.org.br/. Acesso: 12 de jan 2021.
} 
mulheres durante a fase escolar quanto às suas escolha profissionais, tanto no Brasil como no exterior. As instituições de ensino que tem estimulado jovens para disciplinas STEM, tem conseguido promover a equidade de gênero, é o que diz [5]. No trabalho [4], os autores constatam que a participação em programas acadêmicos, impacta positivamente no sucesso e permanência dos estudantes nas áreas STEM, e a escolha de um curso superior na área de computação é fortemente influenciada pela exposição do aluno à atividade de ciência da computação durante o ensino médio, conforme mencionado em [1].

\section{METODOLOGIA}

O Programa Sabará for Women (PS4W) foi criado em 2019, sendo uma derivação do Programa Sabará, projeto que atua no ensino de programação e robótica para jovens das escolas públicas da cidade de Sabará. Por ter foco no público feminino, o PS4W criou uma ampla equipe de meninas e mulheres para atuarem como instrutoras de sete turmas compostas por meninas vindas do ensino público estadual e municipal da cidade.

Foram nove meses de curso, iniciando em março de 2019 e finalizando em novembro do mesmo ano, com conteúdo teórico e prático dividido em quatro módulos: LOGO, Scratch, Python e Robótica, ministrados sequencialmente, os quais totalizavam individualmente 16 horas de aula cada, sendo diluídas em 2 horas semanais. O conteúdo de cada módulo foi escolhido priorizando aperfeiçoar a altivez, o pensamento lógico e a sensorialidade espacial de cada aluna, por trabalhar diferentes campos cognitivos.

A linguagem LOGO [12], criada na década de 1960 no MIT - Massachusetts Institute of Technology, consiste basicamente em fornecer sequências de comandos a uma tartaruga, para que seja possível fazer desenhos na tela. Ela facilita a comunicação entre usuário e máquina, tornando a aluna capaz de solucionar problemas altivamente. Como formação complementar foram ofertadas atividades de computação desplugada baseadas na coleção de materiais didáticos gratuitos que ensinam Ciência da Computação disponibilizados pela organização CS Unplugged ${ }^{8}$. A Figura 1 mostra o registro de uma dinâmica lógica, envolvendo computação desplugada, realizada na primeira aula de cada turma.

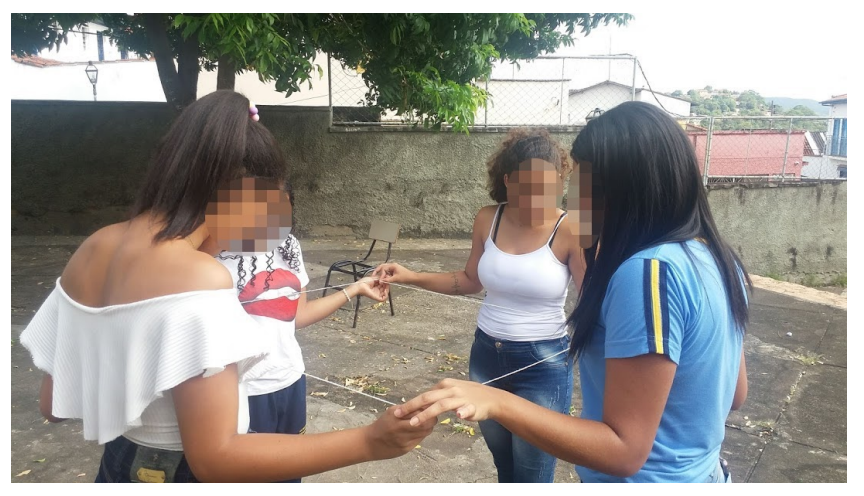

Figura 1: Primeira aula em uma das escolas parceiras do projeto.

$\overline{{ }^{8} \text { Disponível em: }}$ :https://csunplugged.org/en/. Acesso em: 17 jan. 2021.
Contudo, o Scratch ${ }^{9}$, desenvolvido em 2007 pelo mesmo instituto, aplica o princípio de dividir um problema grande em problemas menores e em resolvê-los, imprescindível na programação. Isso se dá porque o Scratch, além de ser uma linguagem visual, sua programação é feita em blocos, o que permite à pessoa criar pequenos blocos de comando, testá-los individualmente e depois uni-los. Todas as aulas ao decorrer do módulo foram baseadas nos materiais ${ }^{10}$ disponibilizados pela comunidade Scratch Brasil visto que a mesma é umas das principais organizações voltadas ao ensino da linguagem no país.

A linguagem Python, muito popular hoje em dia [14], foi escolhida por ter uma sintaxe simples e de fácil aprendizado, se comparada com outras linguagens, e já na primeira aula pode-se começar rapidamente a criar programas simples e vê-los funcionando. Além disso, ela trabalha aos poucos o conhecimento de inglês das alunas, disciplina de língua estrangeira na maioria das escolas. O desenvolvimento tanto dos materiais de consulta como das atividades práticas foi baseado no livro "Ensine seus filhos a programar - Um guia amigável aos pais para programação Python” de Bryson Payne [11], pois segundo palavras de Raj Sunderraman, chefe do departamento de Ciência da Computação da Georgia State University, "os conceitos em Ensine seus filhos a programar podem ajudar qualquer jovem a ter melhores perspectivas para a faculdade e a expandir suas oportunidades de carreira, e Payne apresenta essas habilidades por meio de aplicações e jogos divertidos e desafiadores".

A inclusão do módulo de robótica em um curso voltado para programação possibilitou às instrutoras a adotar uma estratégia de ensino mais didática e dinâmica para que as alunas aplicassem todo o conteúdo passado nos módulos anteriores em um modelo real [8]. É válido lembrar que os conceitos trabalhados nas três linguagens se assemelham muito, como estruturas de repetição e condicionais, o que permitiu que uma aluna que não tivesse entendido o conteúdo em uma linguagem pudesse entendê-lo em outro momento. A Figura 2 trata-se de um logotipo criado pelo projeto, fazendo uma alusão à relação entre os conteúdos.

A partir do financiamento do $\mathrm{CNPq}$ foram criadas bolsas de incentivo a alunas e parceiras do projeto, contemplando 5 professoras das escolas atendidas, 2 alunas em cada turma, 3 bacharelandas do curso de Sistemas de Informação, além de monitoras que cursaram os cursos técnicos em Eletrônica e Informática integrados ao ensino médio do Instituto Federal de Minas Gerais campus Sabará. Ademais, foram fornecidas gratuitamente camisas do projeto para todos os participantes, incluindo voluntários, bolsistas e discentes, como forma de identificação e divulgação do Programa Sabará for Women. O dia da entrega das camisas foi registrado, como mostra a Figura 3.

O Programa Sabará, incluindo seus subprojetos como o PS4W, possuem alguns canais de comunicação e divulgação como:

- Facebook: https://www.facebook.com/programasabara

- Instagram: https://www.instagram.com/programasabara/

- Site: https://sabara.ifmg.edu.br/programasabara/

Estes canais ainda estão em atualização, mas é possível visualizar algumas ações dos projetos de inclusão digital ofertados pelo

\footnotetext{
${ }^{9}$ Disponível em: https://scratch.mit.edu/. Acesso em: 29 abr. 2020.

${ }^{10}$ Disponível em: http://www.scratchbrasil.net.br/index.php/materiais/tutoriais.html. Acesso em:17 jan. 2021.
} 


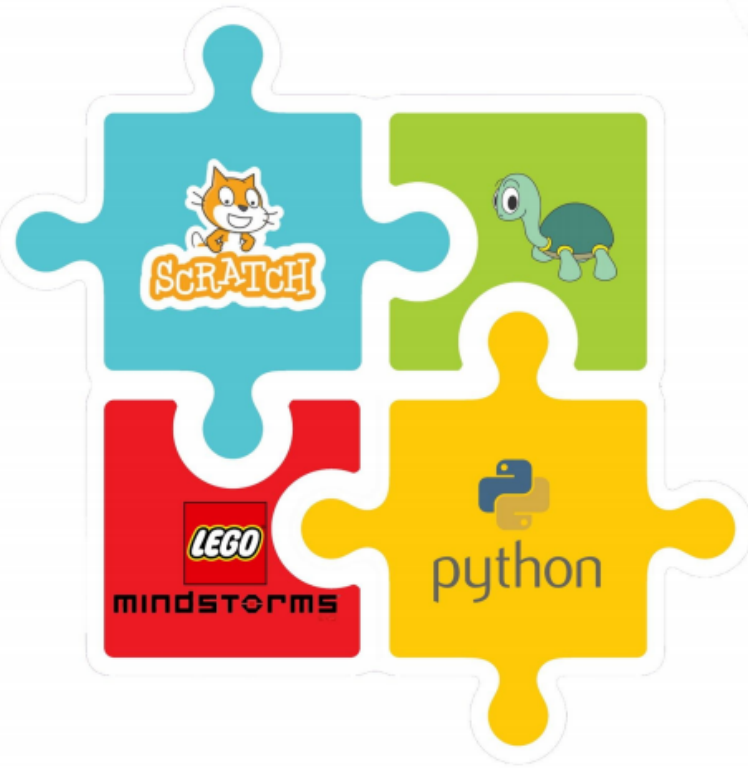

Figura 2: Representação gráfica dos módulos do projeto.

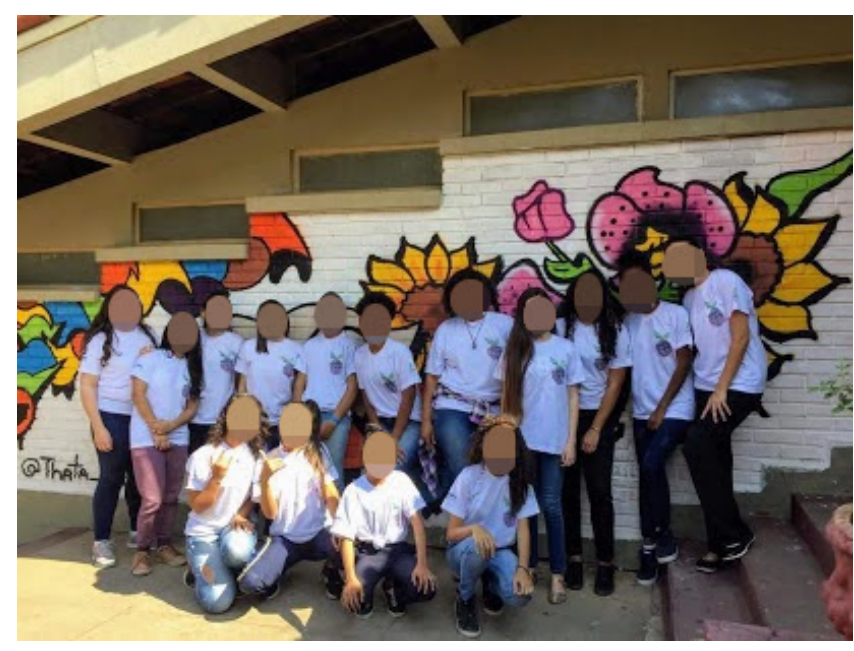

Figura 3: Registro de uma das turmas após receber as camisas do projeto.

Programa Sabará. Posteriormente serão postadas atividades de pensamento computacional e robótica, a fim que estas possam ser replicadas por outras instituições.

\section{DIFICULDADES}

Durante a execução do projeto, surgiram diversas dificuldades, tais como despertar e manter o interesse das meninas; definir uma escala de instrutoras que atendesse todas as turmas, tendo em vista que as mesmas eram alunas de cursos técnicos integrados ou de curso superior, sendo necessário conciliar os horários livres das instrutoras com as aulas do PS4W; localização distante das escolas e de dificuldade no transporte de material. Entretanto, o maior desafio do PS4W foi o quarto e último módulo, robótica. A escassez de recursos fez com que fosse necessário agrupar um maior número de alunas por equipamentos disponíveis.

A robótica inicialmente foi planejada para se basear apenas no conteúdo de LEGO Mindstorms, porém estavam disponíveis para o projeto apenas 4 kits LEGO, para serem utilizados por 7 turmas durante a semana, onde 4 eram atendidas fora do campus. Eventualmente foi considerado transportar o material para as escolas, no entanto o risco de ele ser danificado ou ser perdido era muito grande, diante disso, mudanças se fizeram necessárias.

A primeira alteração foi realocar duas turmas para serem atendidas no campus, contudo foi necessário unir uma das turmas já atendidas no local com uma recém designada, para que fosse compatível com cronograma preexistente de reserva dos laboratórios do campus. Em segundo lugar, as turmas que não puderam ser alocadas no campus tiveram a base do conteúdo de robótica trocado de LEGO para Arduino. Este, foi escolhido por ser um equipamento de menor custo e mais fácil de se transportar, permitindo que mesmo as alunas atendidas in loco também tivessem um módulo inteiramente prático. A Figura 4 mostra alunas de uma das turmas que tiveram a robótica baseada no LEGO realizando um desafio.

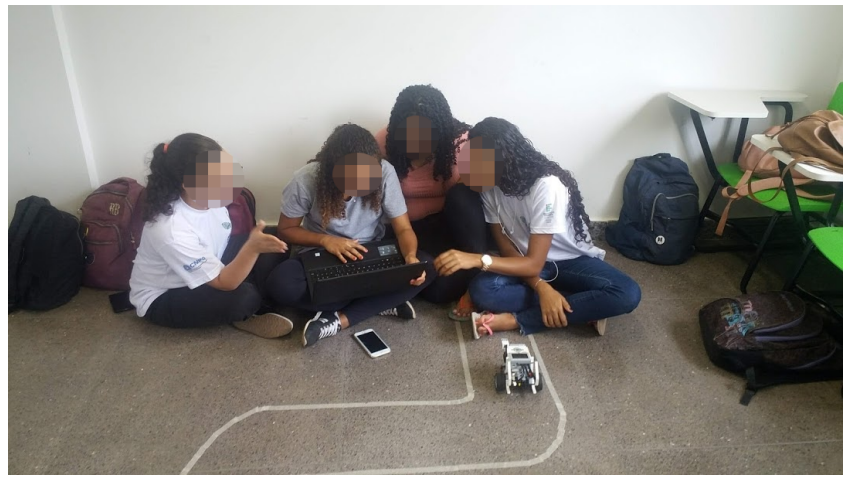

Figura 4: Prática de robótica no laboratório do campus Sabará.

A fim de aprimorar o conhecimento das instrutoras nos conceitos de robótica, tema este mais distante da grade curricular das mesmas, foram realizadas aulas semanais conduzidas por docentes que participavam da equipe, onde eram explicados fundamentos de robótica com base no LEGO e no Arduino, para que as instrutoras alcançassem o domínio do tema. A parte teórica da solução dessas questões foi relativamente fácil, se comparada ao desafio de colocá-las em prática.

Durante todo o curso, foi perceptível a dificuldade das alunas frente a conceitos de matemática básica, lógica e geometria elementar, existindo casos de alunas já no primeiro ano do ensino médio que não conseguem fazer operações matemáticas básicas, como média e potenciação. Esse tipo de dificuldade fez com que as instrutoras tivessem que adiar conteúdo do curso, para ensinar matemática básica, sendo necessário às vezes criar diversas abordagens diferentes da mesma matéria, para que as alunas entendessem a base do que iria ser passado. 
Outro fator que dificultou a execução do projeto foram as regras internas de cada escola, que em alguns casos impossibilitou a realização de determinadas atividades, como por exemplo a instalação de um novo software e a realização de atividades de computação desplugada fora do laboratório. Nesses casos foi necessário que as instrutoras realizassem uma pesquisa para descobrir softwares compatíveis que já estavam instalados nos computadores das escolas e averiguar quais atividades de computação desplugada poderiam ser adaptadas para o ambiente fornecido, em alguns casos sendo necessário a exclusão de tais práticas.

\section{RESULTADOS}

Em seu primeiro ano, o projeto cresceu consideravelmente, onde a partir de uma pequena ideia para ajudar a melhorar o ensino das escolas de uma cidade mineira, se transformou em uma equipe com 36 pessoas, dentre elas bolsistas, voluntários, discentes e docentes, trabalhando para levar conteúdo de qualidade para as alunas atendidas. O programa se tornou conhecido na cidade e a emissora de televisão Rede Minas, decidiu que a primeira reportagem ${ }^{11} \mathrm{de}$ sua série jornalística "Tecnologia Inclusiva" seria a respeito deste projeto, a Figura 5 mostra o momento da gravação. Nela, a aluna do projeto, Mariana, declarou sua experiência: "Aprendi a fazer o robô a andar reto, virar certo, parece bobeira, mas é uma coisa muito dificil". Essa reportagem rendeu à emissora um prêmio nacional de jornalismo na categoria "Televisão", entregue pelo Instituto Federal de Minas Gerais.

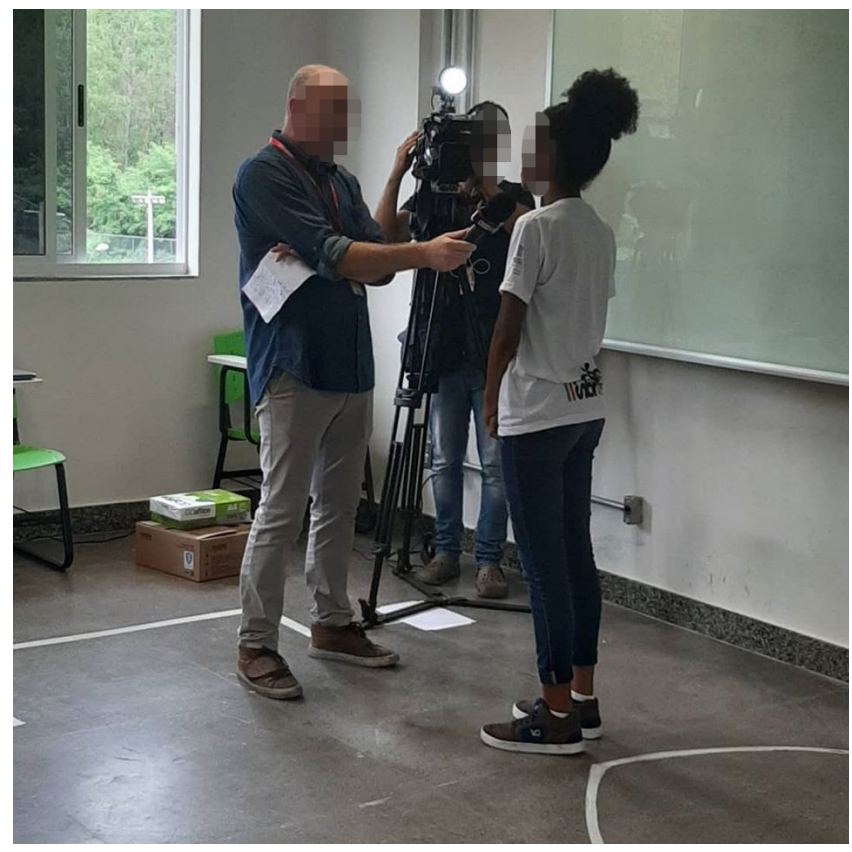

Figura 5: Entrevista sobre o projeto, concedida à emissora Rede Minas.

O PS4W também foi assunto em uma reportagem realizada pelo canal IFMG-Play ${ }^{12}$, onde Alicene Godinho, professora parceira do

\footnotetext{
${ }^{11}$ Disponível em: https://youtu.be/7B7JsKgf-W8. Acesso em: 16 jun. 2020.

${ }^{12}$ Disponível em: https://youtu.be/8Mmt70Mcb8E. Acesso em: 20 abr. 2020.
}

projeto afirmou que "foi o primeiro projeto na escola a ser desenvolvido na área tecnológica, estimulando as mulheres na área de exatas”. O projeto também foi tema de abertura de um seminário de extensão ${ }^{13}$ de um dos principais eventos institucionais do Instituto Federal de Minas Gerais.

Por existir um diálogo aberto entre instrutoras e alunas, foi possível perceber que o impacto das aulas não era apenas no conhecimento, mas também na autoestima e no empoderamento das meninas, conforme a fala (informação verbal) de Jéssica de 14 anos, aluna do projeto: "Esse curso foi e é importante para mim, achei muito inspirador um curso só para meninas, porque aprendi muitas coisas importantes, que levarei para a vida toda e até mesmo me incentivou a seguir a carreira que quero. As professoras do curso me incentivaram a ter a capacidade de fazer as coisas sozinha e isso foi muito importante para mim. Se não fosse tudo o que aprendi aqui, talvez passasse a vida inteira sendo uma menina insegura." Também houve o caso de uma aluna que tinha dificuldades em socializar e, após realizar o curso, seus professores da educação básica relataram informalmente que a aluna teve uma melhora significativa nesse ponto, onde, consequentemente, ela também conseguiu ter um desempenho escolar melhor. As turmas também receberam muito incentivo para participar de atividades extracurriculares e, em uma delas, a Olimpíada Brasileira de Robótica 2019, foram conquistadas três medalhas de honra ao mérito, premiação dada aos melhores de cada turma em cada nível da competição.

A cerimônia de encerramento do PS4W, realizada no Centro Cultural José da Costa Sepúlveda - Cine Bandeirante ${ }^{14}$, foi um evento que marcou todos os envolvidos no projeto, formando 80 meninas de escolas públicas da cidade. Na solenidade, as formandas receberam um certificado de conclusão do curso na presença de aproximadamente de 400 pessoas, entre convidados e familiares. Entre as autoridades presentes na cerimônia de formatura, estavam o diretor-geral do campus Sabará, Daniel Neves Rocha; o coordenador e idealizador do Programa Sabará, Carlos Alexandre Silva; a coordenadora do PS4W, Cristiane Norbiato Targa; o coordenador de gestão das ações de Extensão do IFMG, Matheus Costa Frade; o secretário municipal de Cultura Hamilton Alves, que representou o prefeito da cidade; a secretária municipal de Educação, Vânia Lúcia Leal de Paiva Vieira; e a diretora educacional da Superintendência Regional de Ensino, Márcia Santos Fonseca. A Figura 6 contém registro do evento.

As alunas que se destacaram ao longo do curso, como mostra a Figura 7, receberam uma pequena lembrança do projeto, para mostrar tanto às mesmas quanto a cada uma das outras alunas, que toda equipe se orgulhou muito do desempenho delas e que elas são capazes de atuar onde quiserem.

As instrutoras do PS4W também puderam sentir os benefícios do projeto, pois estar em um ambiente composto por mulheres onde se discute sobre tecnologia também as incentivou a continuar na área, por saberem que, futuramente, podem reencontrar as alunas no mercado de trabalho onde a proporção entre profissionais de diferentes gêneros seja mais equilibrada. A ministração de aulas

\footnotetext{
${ }^{13}$ Disponível em: https://www2.ifmg.edu.br/portal/pesquisa-e-pos-graduacao/planetainovacao-2019/ecossistema-ciencia-e-tecnologia-seminario-de-saberes-daextensao. Acesso em: 20 abr. 2020.

${ }^{14}$ Disponível em: https://sousabara.com.br/empregos/meninas-de-escolas-publicasformam-no-programa-sabara-saiba-mais. Acesso em: 20 abr. 2020.
} 


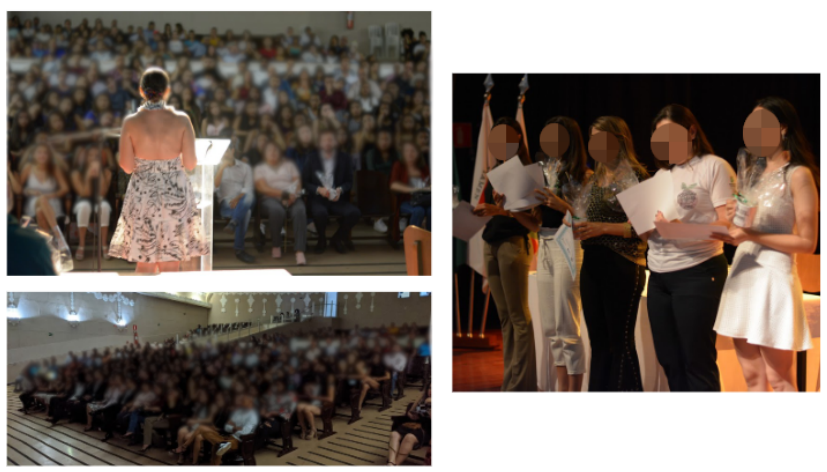

Figura 6: Registros da cerimônia de encerramento do primeiro ano do curso.
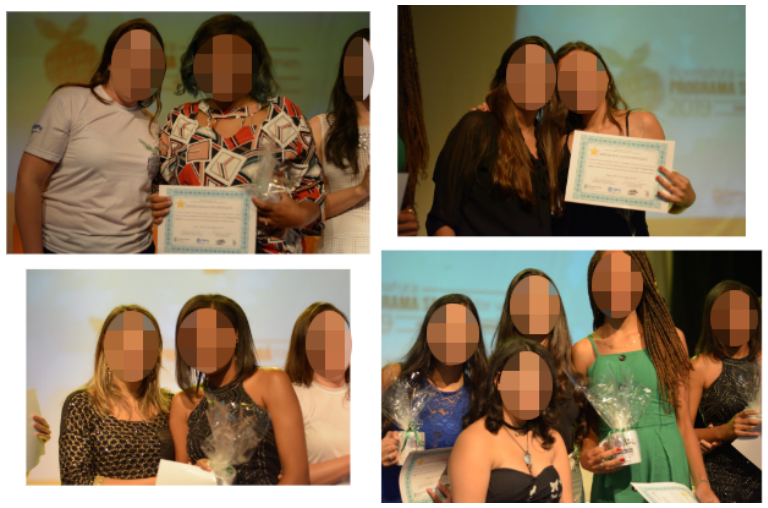

Figura 7: Alunas destaque de cada turma.

deu-lhes mais confiança e proporcionou o aprimoramento da oratória das instrutoras, as quais aprenderam a discursar melhor e, consequentemente, fazer apresentações melhores, tanto no projeto como em seus respectivos cursos. Ademais, uma das instrutoras declarou informalmente: "da forma como a sociedade está estruturada hoje, estar inserida em um ambiente predominantemente masculino é desafiador, porque frequentemente temos que reafirmar a nossa capacidade, então poder dar aulas em um local que eu não precisava ficar provando que sou capaz, era uma válvula de escape para toda essa pressão".

\section{CONSIDERAÇÕES FINAIS}

A iniciativa teve o propósito de levar ensino de programação e robótica para meninas de escolas públicas da cidade de Sabará, a qual, apesar de estar muito próximo da capital do estado de Minas Gerais, não possui as mesmas condições de infraestrutura, educação, saúde, entre outras características. Logo, pode-se dizer que o desenvolvimento do PS4W no município promoveu um passo significativo na evolução da educação tecnológica na cidade, bem como impactou acadêmica e socialmente as envolvidas, tendo em vista que tudo o que foi realizado dependia de uma boa comunicação entre alunas, instrutoras, coordenadoras e escolas parceiras.
Além de proporcionar a inclusão digital, estimular o pensamento computacional e matemático, familiarizar as alunas com linguagens de programação, propiciar o trabalho em equipe, o projeto possibilitou a participação de várias alunas da rede pública de ensino do município em competição nacional.

Também é importante ressaltar que as dificuldades encontradas, relacionadas em sua maioria a limitação de recursos, induziu o programa a pequenas alterações. Apesar de repentinas, elas abriram espaço para novos questionamentos e conclusões sobre o conteúdo, contribuindo assim para o refinamento do projeto.

Como as turmas do PS4W são compostas apenas de meninas, e tanto as instrutoras quanto as professoras envolvidas também são mulheres, o ambiente de aprendizado criado deixou as alunas mais à vontade para participar de aulas de tecnologia e de raciocínio matemático, algo ainda estereotipado como "coisas de menino". As instrutoras, como estudantes do ensino superior do curso de Sistemas de Informação, são potencialmente vistas como exemplos de que a área da computação, e, por extensão, as áreas exatas, são possibilidades de carreira a serem seguidas. Isso gerou um impacto que também afetou os pais e familiares das alunas, os quais sentiram orgulho das mesmas e cobraram a continuação do projeto, para que meninas mais novas, num futuro próximo, também pudessem participar. A longo prazo, espera-se que haja um aumento no número de mulheres interessadas em profissões da área de exatas, por entender que isso também está ao alcance delas. Vale ressaltar que o projeto com as escolas da cidade continua em andamento e uma nova versão foi criada, o "PS4W - Profissional" que capacita meninas e mulheres em desenvolvimento de tecnologia, como criação de sites e aplicativos, especificamente para o mercado de trabalho. Atividades similares sem a diferenciação de gêneros continuam sendo ofertadas pela execução do projeto Programa Sabará.

\section{AGRADECIMENTOS}

A equipe do Programa Sabará for Women agradece ao Instituto Federal de Minas Gerais campus Sabará e ao Conselho Nacional de Desenvolvimento Científico e Tecnológico (CNPq) pelo apoio e financiamento conferido, bem como a todas as bolsistas e voluntários, discentes e docentes, pela diligência e dedicação ao projeto.

\section{REFERÊNCIAS}

[1] Michal Armoni and Judith Gal-Ezer. 2014. High school computer science education paves the way for higher education: the Israeli case. Computer Science Education 24, 2-3 (2014), 101-122.

[2] Edna Dias Canedo, Rodrigo Bonifácio, Márcio Vinicius Okimoto, Alexander Serebrenik, Gustavo Pinto, and Eduardo Monteiro. 2020. Work Practices and Perceptions from Women Core Developers in OSS Communities. In Proceedings of the 14th ACM/IEEE International Symposium on Empirical Software Engineering and Measurement (ESEM). 1-11.

[3] Wendell Bento Geraldes. 2014. Programar é bom para as crianças? Uma visão crítica sobre o ensino de programação nas escolas. Texto Livre: Linguagem e Tecnologia 7, 2 (2014), 105-117.

[4] Michael A Gottfried and Darryl Williams. 2013. STEM club participation and STEM schooling outcomes. education policy analysis archives 21 (2013), 79.

[5] Joscha Legewie and Thomas A DiPrete. 2014. The high school environment and the gender gap in science and engineering. Sociology of Education 87, 4 (2014), 259-280.

[6] Betina Stefanello Lima, Maria Lúcia de Santana Braga, and Isabel Tavares. 2016. Participação das mulheres nas ciências e tecnologias: entre espaços ocupados e lacunas. Revista Gênero 16, 1 (2016).

[7] Pedro Jácome de Moura Junior and Diogo Henrique Helal. 2014. Profissionais e profissionalização em Tecnologia da Informação: indicativos de controvérsias e conflitos. Cadernos EBAPE. BR 12, 2 (2014), 321-338. 
[8] Geraldo Furtado Neto, Bruno Leandro Esteves da Silva, Rondineli Rodrigues Pereira, and Lindolpho Oliveira de Araújo Júnior. 2012. Utilização do kit Lego Mindstorm NXT no Ensino de Controle de Processos. In Anais do XL Congresso Brasileiro de Educação em Engenharia. 03-06.

[9] Gilda Olinto. 2011. A inclusão das mulheres nas carreiras de ciência e tecnologia no Brasil. Inclusão Social 5, 1 (2011).

[10] Elisabete Regina Baptista de Oliveira, Sandra Unbehaum, and Thais Gava. 2019 A educação STEM e gênero: uma contribuição para o debate brasileiro. Cadernos de Pesquisa 49, 171 (2019), 130-159.

[11] Bryson Payne. 2015. Ensine seus filhos a programar: Um guia amigável aos pais para a programação Python. Novatec Editora, Brasil.
[12] Dagmar Heil POCRIFKA and Taís Wojciechowski SANTOS. 2009. Linguagem LOGO e a Construção do Conhecimento. In IX Congresso Nacional de educação e III Encontro Sul Brasileiros de Psicopedagogia. PUCPR, curitiba.

[13] Ahmed Tareq Rashid. 2016. Digital inclusion and social inequality: Gender differences in ICT access and use in five developing countries. Gender, Technology and Development 20, 3 (2016), 306-332.

[14] Rodrigo Duarte Seabra, Isabela Neves Drummond, and Fernando Coelho Gomes. 2018. ANÁLISE COMPARATIVA DE LINGUAGENS DE PROGRAMAÇÃO A PARTIR DE PROBLEMAS CLÁSSICOS DA COMPUTAÇÃO. Revista de Sistemas e Computação-RSC 8, 1 (2018).

[15] OBSERVATÓRIO SOFTEX. 2013. Mercado de trabalho e formação de mão de obra em TI. Cadernos Temáticos do Observatório. Observatório SOFTEX (2013). 